\title{
Organic Semiconductor Laser Platform for the Detection of DNA by AgNP Plasmonic Enhancement
}

\author{
G. McConnell, ${ }^{\dagger, \ddagger \odot ~ S . ~ M a b b o t t, ~}{ }^{\S}$ A. L. Kanibolotsky, ${ }^{\|, \perp, \nabla}$ P. J. Skabara, ${ }^{\|, \#}$ D. Graham, ${ }^{\S}$ G. A. Burley, ${ }^{\S}$ \\ and N. Laurand ${ }^{*} \dagger$ \\ ${ }^{\dagger}$ Institute of Photonics, Department of Physics, University of Strathclyde, Glasgow G12 8QQ U.K. \\ ${ }^{\ddagger}$ Biomedical Engineering, University of Strathclyde, Glasgow G12 8QQ U.K. \\ ${ }^{\S}$ WestCHEM, Department of Pure and Applied Chemistry, University of Strathclyde, Glasgow G12 8QQ, U.K. \\ "WestCHEM, School of Chemistry, University of Glasgow, Glasgow G12 8QQ U.K. \\ ${ }^{\perp}$ Institute of Physical-Organic and Coal Chemistry, The National Academy of Sciences of Ukraine, 02160 Kyiv, Ukraine
}

Supporting Information

ABSTRACT: Organic semiconductor lasers are a sensitive biosensing platform that respond to specific biomolecule binding events. So far, such biosensors have utilized proteinbased interactions for surface functionalization but a nucleic acid-based strategy would considerably widen their utility as a general biodiagnostic platform. This manuscript reports two important advances for DNA-based sensing using an organic semiconductor (OS) distributed feedback (DFB) laser. First, the immobilization of alkyne-tagged 12/18-mer oligodeoxyribonucleotide (ODN) probes by $\mathrm{Cu}$-catalyzed azide alkyne cycloaddition (CuAAC) or "click-chemistry" onto an $80 \mathrm{~nm}$

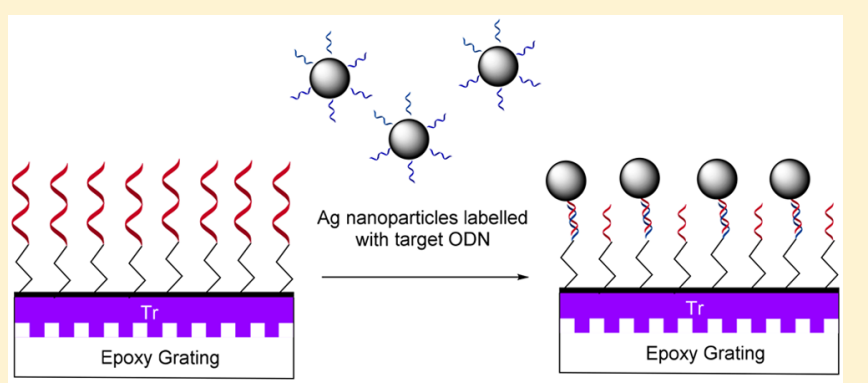
thick OS laser film modified with an azide-presenting polyelectrolyte monolayer is presented. Second, sequence-selective binding to these immobilized probes with complementary ODN-functionalized silver nanoparticles, is detected. As binding occurs, the nanoparticles increase the optical losses of the laser mode through plasmonic scattering and absorption, and this causes a rise in the threshold pump energy required for laser action that is proportional to the analyte concentration. By monitoring this threshold, detection of the complementary ODN target down to $11.5 \mathrm{pM}$ is achieved. This complementary binding on the laser surface is independently confirmed through surface-enhanced Raman spectroscopy (SERS).

\section{INTRODUCTION}

A range of biological materials such as circulating micro$\mathrm{RNA}^{1-4}{ }^{8 N A},{ }^{5-7}$ and proteins, ${ }^{8-11}$ which are found in the blood, plasma, or other biological fluids, can be used as biomarkers for patient diagnosis, identifying disease pathologies and risk groups. ${ }^{12,13}$ While standard biomarker detection is carried out in centralized laboratories, approaches to medicine for early disease prevention, ${ }^{14}$ triaging, and chronic disease management ${ }^{15}$ necessitate the development of point-of-care diagnostic technologies to provide rapid results in nonlaboratory settings. ${ }^{16,17}$ There are several promising optical technologies for this need in point-of-care diagnostics, ${ }^{18-21}$ some of them combining evanescent sensing platforms with antibody protein or nucleic acid (DNA sensing) biorecognition approaches. The current technologies are subject to limitations, discussed here in more detail, which the new paradigm presented in this text hopes to address.

Most evanescent wave sensors are based on passive, optically resonant structures such as dielectric microresonators, ${ }^{21-23}$ photonic crystals, ${ }^{24-26}$ or surface plasmon resonators. ${ }^{27,28}$ However, they necessitate precise injection of an external light source to the resonator, which complicates their miniatur- ization and further leads to a trade-off between sensitivity and detection resolution. ${ }^{29}$ Organic distributed feedback (DFB) laser sensors offer a viable alternative to these passive evanescent wave devices. They mitigate the sensitivity/ resolution trade-off issue, and their facile implementation is attractive for miniaturization. ${ }^{29-32}$ Organic DFB laser sensors are fabricated by imprinting a nanofilm of lasing material with a Bragg grating structure. Their emission properties are responsive to changes in the refractive index at the surface of the nanofilm. ${ }^{19,32}$ The laser material is either a transparent polymeric matrix doped with dyes ${ }^{33-36}$ or an organic semiconductor (OS) as we previously reported. ${ }^{37-39}$

Biosensing with organic DFB lasers has so far exclusively relied on antibodies or antigens for biomarker capture and on measuring the shift of the laser wavelength for transduction. Demonstrating a nucleic acid strategy for biomarker capture is

Special Issue: Nucleic Acids Nanoscience at Interfaces

Received: April 22, 2018

Revised: September 15, 2018

Published: September 18, 2018 

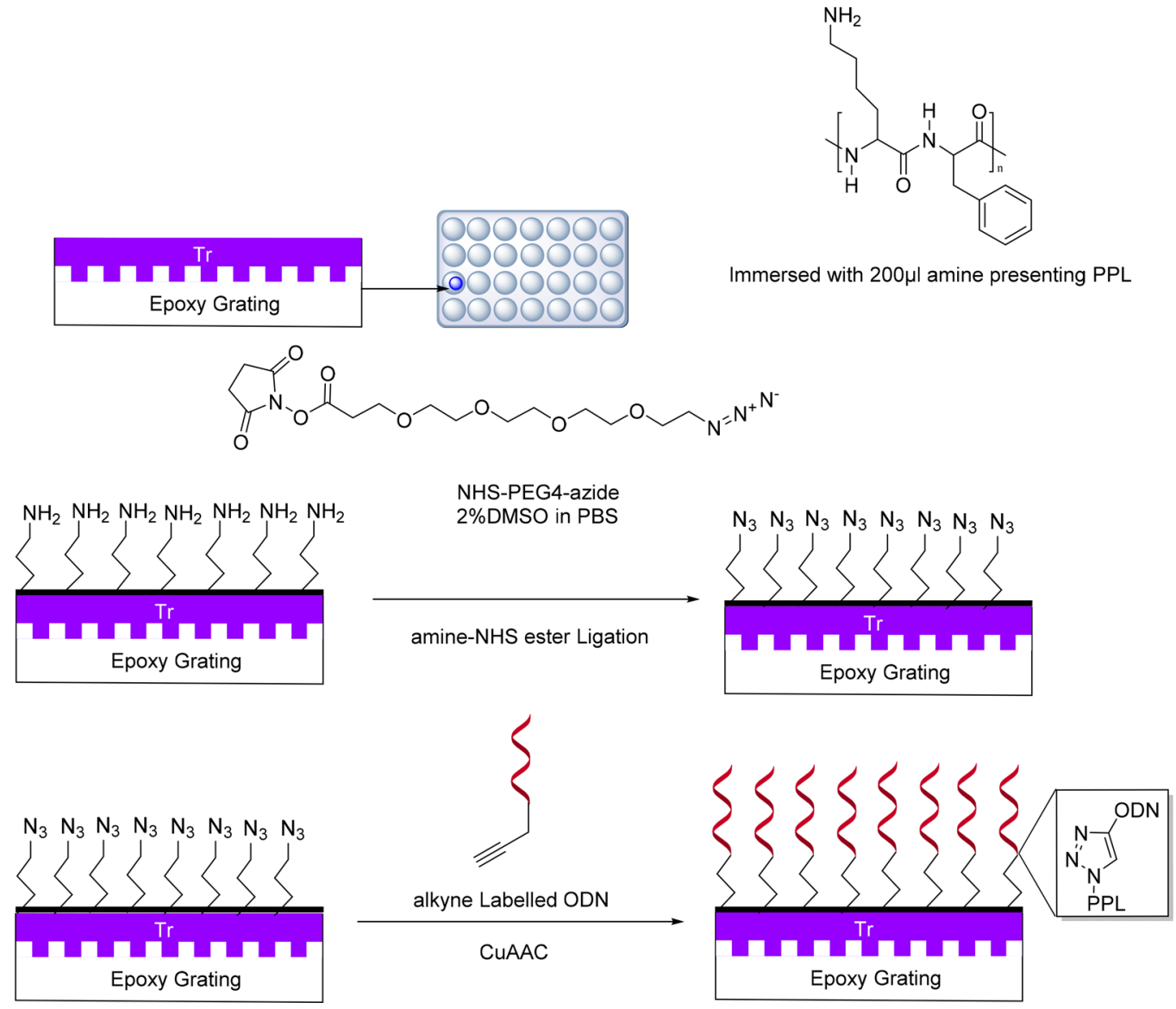

Figure 1. Stepwise functionalization of an organic DFB laser with ODN probes for the capture of matching ODN sequences (not to scale).

of interest because DNA probes are more robust, less costly to produce and they can be flexibly designed to target particular biomarkers and tailored for reuse. ${ }^{40,41}$ Furthermore, devices have been shown to specifically detect IgG with a limit of detection (LOD) of $60 \mathrm{ng} / \mathrm{mL},{ }^{42}$ TNF- $\alpha$ at a LOD of 0.625 $\mu \mathrm{g} / \mathrm{mL},{ }^{43}$ and ErbB2 protein biomarkers at a LOD of $14 \mathrm{ng} /$ $\mathrm{mL} .{ }^{32}$ While these are within the diagnostic ranges of a few medically relevant biomarkers, such LODs are still too large for many disease biomarkers where a LOD in the range of $\mathrm{pg} / \mathrm{mL}$ or pM is often needed. ${ }^{44}$ Therefore, there is a distinct need to lower the LOD, which can be achieved using plasmonic nanoparticles to amplify the change in complex refractive index upon biomarker binding to the laser surface and monitoring laser characteristics other than the wavelength.

We describe herein the preparation of an OS DFB laser functionalized with 12/18-mer oligodeoxyribonucleotides (ODNs). Using the $\mathrm{Cu}$-catalyzed alkyne-azide cycloaddition (CuAAC) reaction or "click-chemistry", DNA immobilization $^{45-48}$ is achieved by the formation of a 1,4-triazole on the surface by the reaction of a $5^{\prime}$-modified ODN sequence with an azide-modified OS surface. This enables the detection of the sequence-selective binding of silver nanoparticle (AgNP) functionalized with complementary ODN sequences. AgNPs allow confirmation of surface immobilization through SERS measurements, ${ }^{49}$ but they also significantly increase, via localized surface plasmons, the effect on the laser characteristics. In this paper, we demonstrate sequence-selective detection of ODN analytes using a hybrid DNA/organic laser in conjunction with SERS active AgNPs, which is a recent evanescent sensor platform.

\section{EXPERIMENTAL METHODS}

DFB Laser Fabrication. The DFB lasers are made of a thin layer of gain material deposited on top of an epoxy grating. The grating enables feedback for laser oscillation but also provides outcoupling of the emission perpendicular to the gain material film for a vertical emission. Epoxy gratings, with a periodicity of $\Lambda=276 \mathrm{~nm}$ and a 5 $\mathrm{mm}$ by $5 \mathrm{~mm}$ surface area, ${ }^{37}$ were fabricated by imprinting a Norland NOA65 epoxy, dropped onto an acetate mount, with a silica master grating (made by e-beam lithography) and UV curing it for $50 \mathrm{~s}$ under a UV lamp for a dosage of $300 \mathrm{~J} \cdot \mathrm{cm}^{-2}$ and further postcuring for $1 \mathrm{~h}$ to stabilize the structure after removal from the master grating. Vertically emitting DFB lasers were then obtained by forming a $\approx 80$ $\mathrm{nm}$ thick nanofilm of neat $\mathrm{T} 3$ oligofluorene-truxene star-shaped macromolecules, consisting of truxene core and three terfluorene $\operatorname{arms}^{50-52}(\mathrm{Tr})$, onto an epoxy grating. The film was deposited by spin-coating $15 \mathrm{~mL}$ of a $20 \mathrm{mg} \cdot \mathrm{mL}^{-1} \mathrm{Tr}$ in toluene solution onto an acetate mounted grating taped to a glass support at $3.2 \mathrm{krpm}$. The DFB lasers were transferred and taped into the bottom of a well in a well plate as schematized in Figure 1. This arrangement enabled easy immersion of the lasers for the different steps of surface functionalization, biohybridization, and characterization, as detailed below.

Surface Functionalization/Probe Immobilization. Azidemodified laser surfaces were prepared by exposing the amine presenting poly(phenyl-lysine) (PPL) monolayer coated OS surface to a $200 \mu \mathrm{L}$ droplet of a $2 \mathrm{mg} \cdot \mathrm{mL}^{-1}$ azido- $\mathrm{PEG}_{4}-\mathrm{NHS}$ ester (Figure 1 ) solution for $15 \mathrm{~min}$. This enables subsequent "click" immobilization of alkyne labeled ODNs.

For this, the OS laser surface is first washed with a $10 \mathrm{mM}$ phosphate buffer solution (PBS). The laser is then coated with PPL (a polyelectrolyte containing lysine with amine ligation sites) by immersion for $10 \mathrm{~min}$ in PPL suspended in PBS. The laser surface 
is washed with PBS again to remove any loose material before azide modification of the adsorbed PPL layer.

For the probes, ODN sequences $\left(\mathrm{ODN}_{x p}\right.$, where $x=1,2$, or 3 , corresponds to different sequences as identified in Figure 2) were

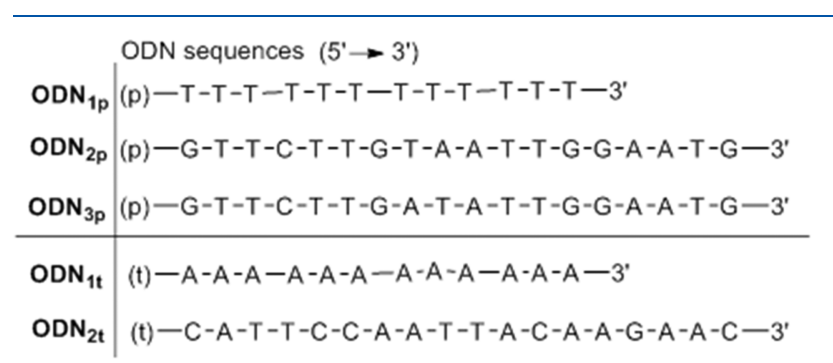

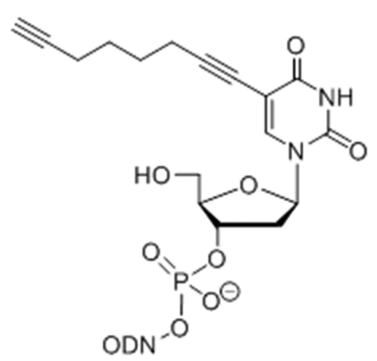

$T_{\text {alkyne }}$ probe modifier $(p)$
Thiol target modifier $(\mathrm{t})$<smiles>CC(CCCOCCOP(=O)([O-])OON)OON</smiles>

Figure 2. ODN probe/target sequences shown with $(t)$ thiol modification for NP labeling and ( $\mathrm{p}$ ) alkyne modification for clickchemistry.

purchased with an alkyne group at the $5^{\prime}$ end to enable click immobilization on the azide presenting laser surface. To immobilize these probes on the lasers, $17.5 \mathrm{nmol}$ of an $\mathrm{ODN}_{x p}$ in deionized water with copper(II) sulfate, $35 \mathrm{nmol}$ of sodium ascorbate, and $35 \mathrm{nmol}$ of THPTA were incubated for $30 \mathrm{~min}$. The surface was then washed with PBS.

Biohybridization for Target Detection. For the targets, ODN sequences $\left(\mathrm{ODN}_{y}\right.$, where $y=1$ or 2 , corresponds to two different sequences; see Figure 2) were purchased with a terminal thiol at the $5^{\prime}$ end. These were used to functionalize $\mathrm{AgNPs}^{49}$ (approximately $40-45 \mathrm{~nm}$ in diameter) labeled with malachite green isothiocyanate (MGITC) dye that was used for SERS detection. DNA/MGITC:NP ratios of 5000:1 in excess were used for AgNP functionalization. ${ }^{53}$ $\mathrm{ODN}_{1 \mathrm{t}}$, a 12-mer consisting solely of adenines was matched to the probe $\mathrm{ODN}_{1 \mathrm{p}}$, a 12-mer of the base thymine; these were used in initial experiments to confirm the anchoring of the ODN probes via clickchemistry. $\mathrm{ODN}_{2 t}$ is the complementary 18-mer to the mixed sequence probe $\mathrm{ODN}_{2 \mathrm{p}}$. $\mathrm{ODN}_{3 \mathrm{p}}$ is mismatched to $\mathrm{ODN}_{2 \mathrm{t}}$ with bases 8 and 9 reversed from $\mathrm{ODN}_{2 \mathrm{p}}$. These 18 -mer ODNs were used in experiments to assess the specificity of the ODN target/analyte hybridization at the functionalized DFB surface.

For ODN analyte detection, the $\mathrm{ODN}_{x \mathrm{p}}$-functionalized DFB lasers were incubated with target $\mathrm{ODN}_{\mathrm{yt}}$ bound AgNPs in solution (PBS with $0.3 \mathrm{M} \mathrm{NaCl}$ ) for $30 \mathrm{~min}$ ( $10 \mathrm{~min}$ for threshold comparison).

Surface-Enhanced Raman Spectroscopy 2D Mapping. Mapping was carried out using a Raman microscope (Gloucestershire, U.K.) equipped with an excitation wavelength of $514.5 \mathrm{~nm}$. Light was focused on the samples using a $20 \times$ objective, and the Raman shift was calibrated using a Si standard peak fixed at $520.5 \mathrm{~cm}^{-1}$. Spectra of each sample were collected for $0.5 \mathrm{~s}$ in a $680-6080 \mathrm{~cm}^{-1}$ spectral range. The SERS peak present close to $1171 \mathrm{~cm}^{-1}$ corresponding to the in-plane $\mathrm{C}-\mathrm{H}$ bending of MGITC was used to track the AgNP distribution across the surface. ${ }^{49}$ The SERS data was baseline corrected, and the intensity of the signature of MGITC, indicative of the presence of AgNPs, was used to generate surface maps with $0.01 \mu \mathrm{m}$ spatial resolution.
Optical Pumping and Laser Characterization. The lasers were fixed in the wells with Kapton tape and optically pumped through the bottom of the well, perpendicular to the plane of the DFB laser surface, so the functionalized surface would not affect the incident pump laser beam. The pump laser emitted $355 \mathrm{~nm}$ wavelength pulses of $5 \mathrm{~ns}$ duration at a $10 \mathrm{~Hz}$ repetition rate. The DFB vertical laser emission was collected from the same side as the pump injection (i.e., from the bottom of the well) using a dichroic filter. It was coupled into a $50 \mu \mathrm{m}$ core fiber plugged into a CCD spectrometer (Avantes, $0.13 \mathrm{~nm}$ resolution) for spectra and intensity acquisition. The ODNfunctionalized DFB laser typically emits at $430 \mathrm{~nm}$ for a line width below $0.3 \mathrm{~nm}$ and has a threshold of $0.06 \mu \mathrm{J}( \pm 7 \%)$ when measured in PBS with a pump spot of $\approx 140 \mu \mathrm{m}$ in diameter (using the $\mathrm{e}^{-2}$ of the intensity maximum). More details on the PL and amplified spontaneous emission spectra of the $\operatorname{Tr}$ gain material can be found in the literature. ${ }^{38}$ Figure 3 plots a typical Tr DFB laser emission

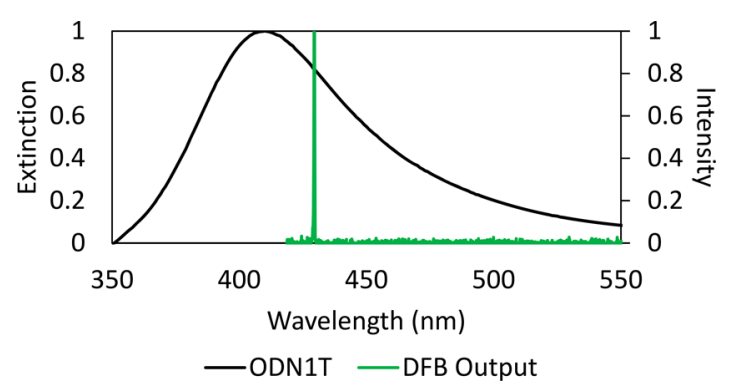

Figure 3. Normalized extinction spectrum for AgNPs coated with ODN targets with overlay of typical DFB laser output in green.

spectrum in PBS alongside the extinction spectrum of ODN coated AgNPs. The laser transfer function, which is obtained by plotting the integrated spectral intensity of the laser versus the pump energy, was characterized for different target concentrations. This analysis allowed the effect of the AgNP hybridization on the DFB laser performance to be determined. The DFB laser output in the presence of AgNPs is discussed later in the text and Supporting Information. SEM images of DFBs exposed to target AgNPs in solution can be seen in SI1, SEM Imaging.

\section{RESULTS AND DISCUSSION}

Initially, we studied the effectiveness of our laser surface functionalization strategy using the poly-T probes $\mathrm{ODN}_{1 \mathrm{p}}$. We did this by capturing a 2D SERS map of laser devices functionalized with $\mathrm{ODN}_{1 \mathrm{p}}$ probes, different samples prepared with and without an intermediate PPL monolayer, and nonfunctionalized lasers consisting of only the neat Tr OS film.

Figure 4a represents the SERS spectrum of a particular point on the surface of a functionalized DFB laser before and after $\mathrm{ODN}_{1 \mathrm{t}}$ coated AgNPs have hybridized to the $\mathrm{ODN}_{1 \mathrm{p}}$ probes bound to the DFB surface. A $130 \times 130 \mu \mathrm{m}^{2}$ 2D SERS map is generated by laser excitation of the DFB laser surface under study, and it is utilized in the following to validate the laser surface functionalization and capabilities for complementary strand detection. The peak present at $1615 \mathrm{~cm}^{-1}$ and amplified in the samples where MGITC labeled AgNPs have bound to the surface is due to $\mathrm{N}-\mathrm{Ph}$ ring vibration and $\mathrm{C}-\mathrm{C}$ stretch; these features can be found in the OS layer, and $1170 \mathrm{~cm}^{-1}$ is a signature peak of MGITC. In Figure $4 b$, as evidenced by the SERS signal intensity shown in the SERS maps, it can clearly be seen that the AgNPs bound with $\mathrm{ODN}_{1 \mathrm{t}}$ have hybridized to the fully functionalized laser (when functionalization includes the PPL layer as described in Experimental Methods) with much greater affinity than any of the other two samples. 

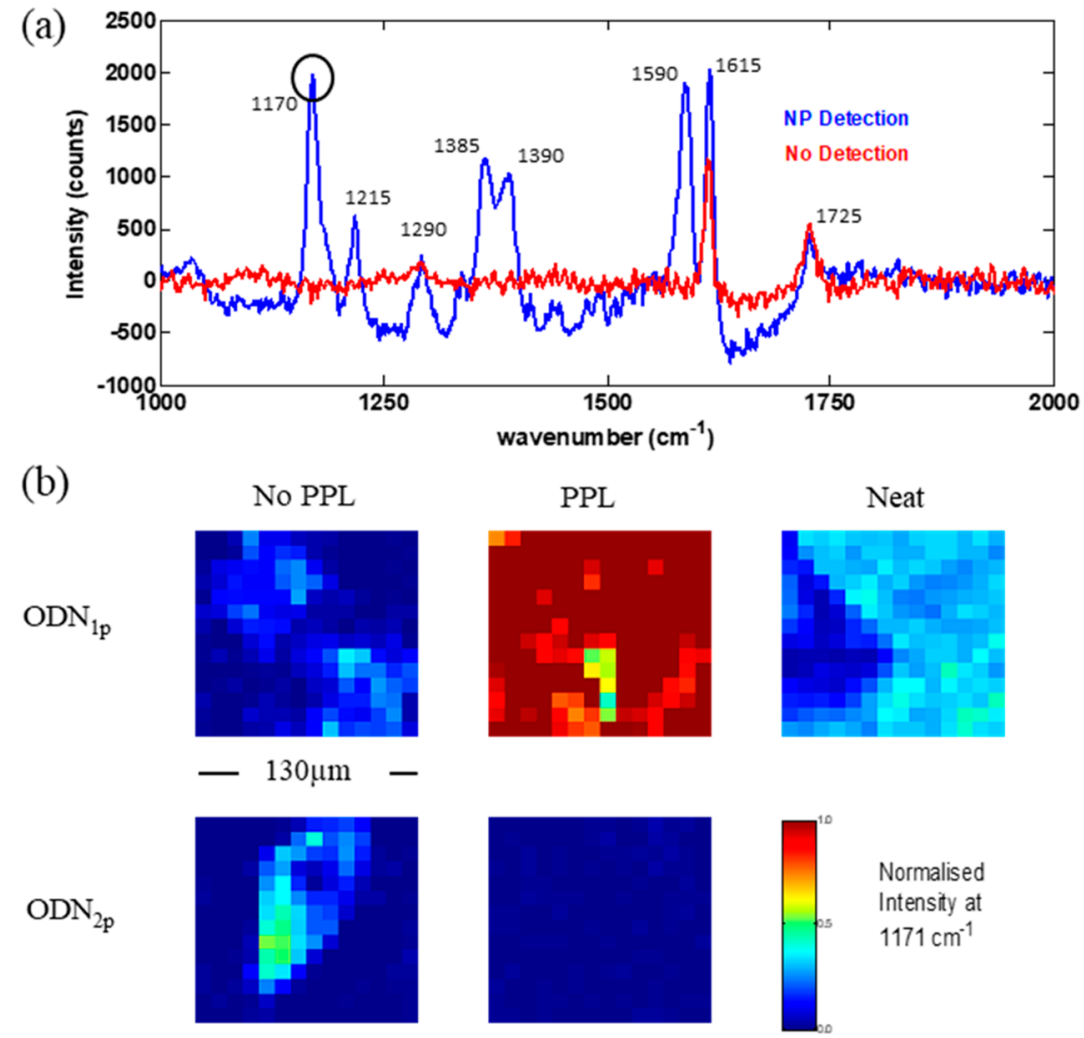

Figure 4. (a) SERS spectra of a DFB laser before (red) and after (blue) ODN ${ }_{1 \mathrm{t}}$ incubation. (b) SERS mapping of OS-DFB surfaces demonstrating the effects of including a PPL layer on the target bound AgNP hybridization and the specificity of NP absorption. All samples were exposed to $\mathrm{ODN}_{1 \mathrm{t}}$.

(a)

ODN

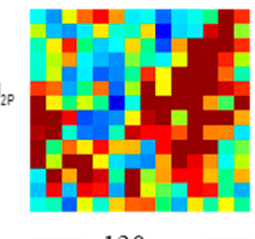

(b)

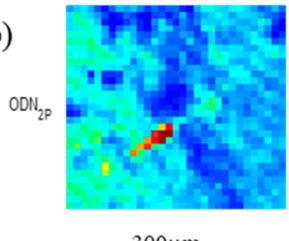

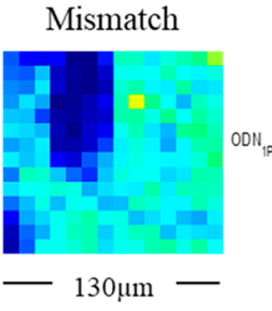

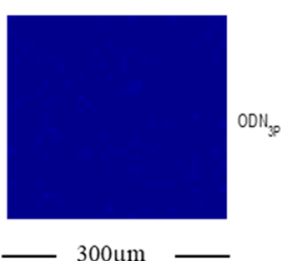

(c)

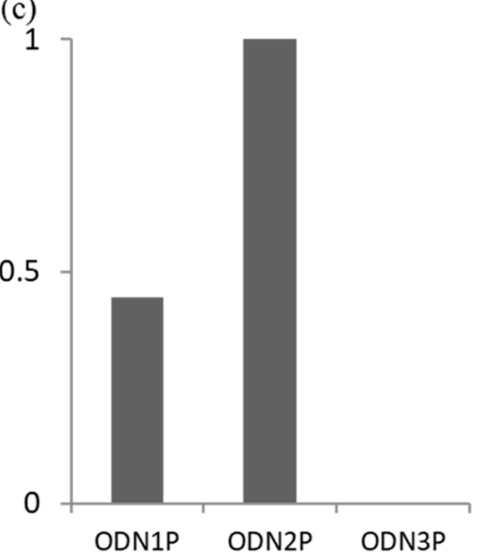

Figure 5. SERS mapping used in specificity testing of samples when exposed to mixed sequence $\mathrm{ODN}_{2 \mathrm{~T}}$ comparing samples coated with the targeted probe $\mathrm{ODN}_{2 \mathrm{P}}$ to (a) $\mathrm{ODN}_{1 \mathrm{P}}$, a poly-A chain, and (b) $\mathrm{ODN}_{3 \mathrm{P}}$, a chain with nucleotides 8 and 9 reversed. (c) Mean intensity of samples exposed to solution containing $\mathrm{ODN}_{2 \mathrm{~T}}$, which is complementary to $\mathrm{ODN}_{2 \mathrm{P}}$, normalized to the intensity value of the ODN $\mathrm{OP}_{2 \mathrm{P}}$ sample.

The neat DFB laser surface displays a higher MGITC signal than the partially functionalized sample; this suggests that some nonspecific adsorption (NSA) of $\mathrm{ODN}_{1 \mathrm{t}}$ coated AgNPs directly onto the $\operatorname{Tr}$ film is taking place. We suspect that the ODNs adsorb onto $\mathrm{Tr}$ through their hydrophobic bases leaving the hydrophilic backbone facing up. The lower level of NSA on partially functionalized samples (where PPL is omitted) is indicative of ODN probes nonspecifically adsorbed to the $\operatorname{Tr}$ film. The adsorbed probes cannot easily react with the targets but are impeding NSA of the latter on the laser surface.
Samples functionalized with $\mathrm{ODN}_{2 \mathrm{p}}$ mixed sequence probes, i.e., mismatched to $\mathrm{ODN}_{1 \mathrm{v}}$, show a much lower intensity 1171 $\mathrm{cm}^{-1}$ signature peak for MGITC in Figure $4 \mathrm{~b}$ demonstrating specificity in the binding. The $\mathrm{ODN}_{1 \mathrm{t}}-\mathrm{ODN}_{1 \mathrm{p}}$ binding used to assess the CuAAC protocol is useful due to the high binding affinity between poly-A and poly-T ODN sequences. However, in a second set of experiments, to verify the practicality and specificity of this protocol for biosensing, we replaced these with mixed sequence ODNs. $\mathrm{ODN}_{2 \mathrm{t}}$ is a mixed sequence 18mer $\mathrm{ODN}$ while $\mathrm{ODN}_{2 \mathrm{p}}$ and $\mathrm{ODN}_{3 \mathrm{p}}$ are the complementary and mutated sequences (two reversed base sequences), 


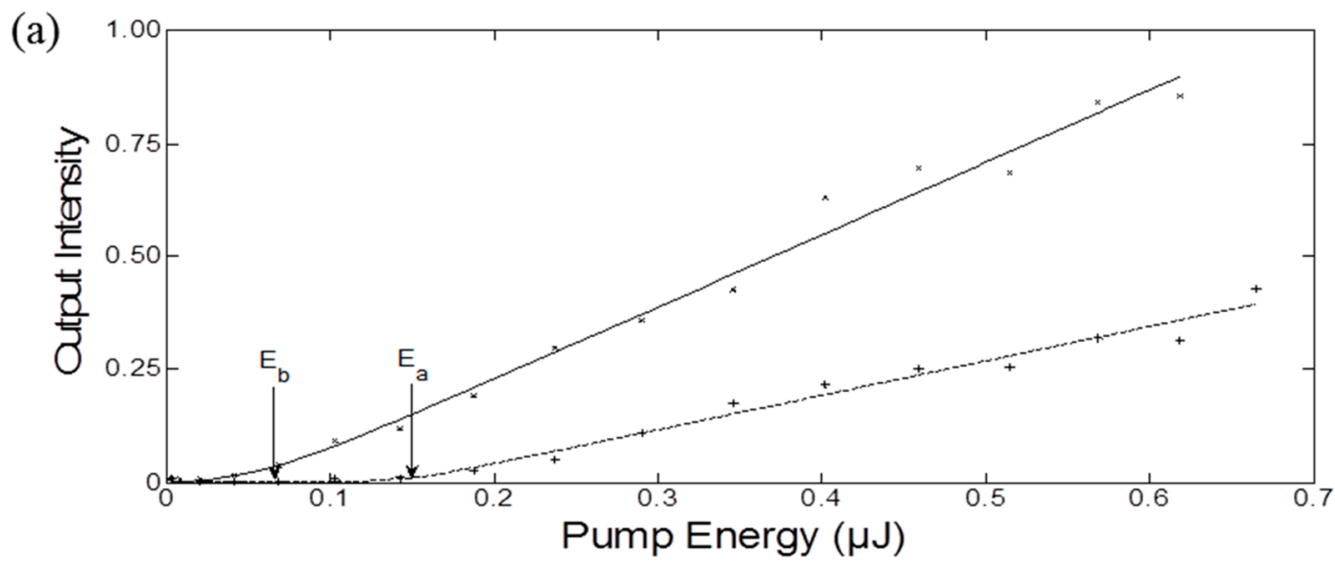

(b)

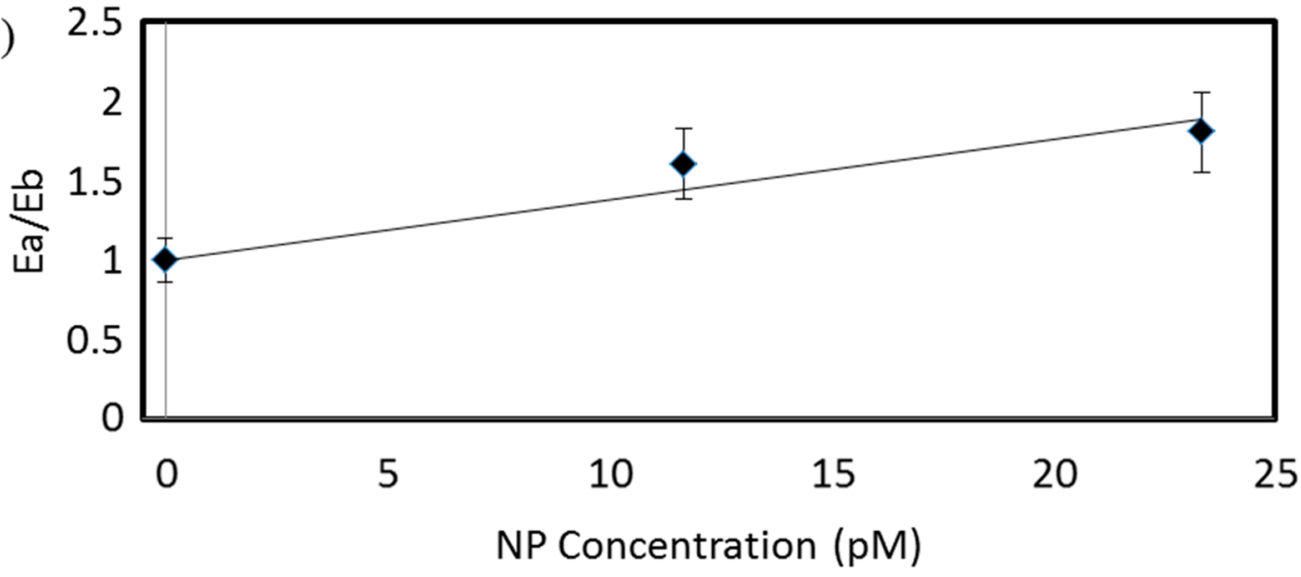

(c)
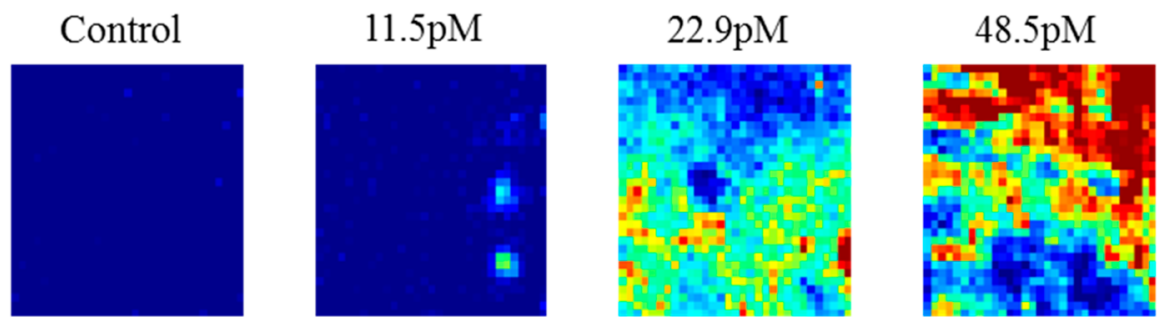

Figure 6. (a) Laser transfer function fitted curves before and after AgNP hybridization. The threshold energy after $\left(E_{\mathrm{a}}\right)$ hybridization has increased compared to that before $\left(E_{\mathrm{b}}\right)$ hybridization. (b) The ratio between the lasing threshold after $\left(E_{\mathrm{a}}\right)$ and before $\left(E_{\mathrm{b}}\right)$ incubation of a Tr DFB laser functionalized with $\mathrm{ODN}_{1 \mathrm{p}}$ probes exposed to varying concentrations of $\mathrm{ODN}_{1 \mathrm{t}}$ with a standard deviation of $7 \%$ measured in the pump beam. (c) SERS maps of the corresponding laser surfaces.

respectively. The use of 18 -mer rather than the 12 -mer ODN sequences is also closer to the $\approx 20$-mer ODN sequences usually attributed to micro-RNA. ${ }^{4}$

$\mathrm{ODN}_{1 \mathrm{p}}$-functionalized, $\mathrm{ODN}_{2 \mathrm{p}}$-functionalized, and $\mathrm{ODN}_{3 \mathrm{p}}$ functionalized lasers were exposed to $\mathrm{ODN}_{2 \mathrm{t}}$ labeled AgNPs. Results for both experiments are shown in Figure 5. The $\mathrm{ODN}_{2 \mathrm{p}}$-functionalized sample demonstrates a far greater binding affinity with the target $\mathrm{ODN}_{2 \mathrm{t}}$ labeled NPs. In fact, the sample with $\mathrm{ODN}_{3 \mathrm{p}}$ probes shows very little binding to the target NPs. In Figure 5b, the sample surface was also mapped over an increased area, $300 \times 300 \mu \mathrm{m}^{2}$, to give a more complete picture of the binding homogeneity across the laser surface, but this decreases the accuracy in the presence of localized regions of high intensity as a wider range of values are represented by the same 256 color scale through normalization.

Figure 5c shows the normalized comparison of the average pixel heatmap for surfaces prepared with different ODN probes across the inspected area. As can be seen, the $\mathrm{ODN}_{3 \mathrm{p}^{-}}$ functionalized lasers show almost no binding while the poly-T $\mathrm{ODN}_{1 \mathrm{t}}$ probe does show some signs of AgNP capture; this is thought to be due to a lower specificity exhibited by the mononucleotide as opposed to mixed sequence ODN probes.

After confirmation by SERS of the immobilization of ODN probes and of the specificity of target hybridization, we characterized the effect of such hybridization on the DFB laser output using $\mathrm{ODN}_{1 \mathrm{t}}$ targets and $\mathrm{ODN}_{1 \mathrm{p}}$ surface probes. The AgNPs of bound target ODNs are immobilized at an average distance of $10-15 \mathrm{~nm}$ from the laser surface (added length of the PPL layer, the azido- $\mathrm{PEG}_{4}$-NHS ester, and the ODN probe), and therefore, the laser mode is able to couple to them by evanescence. ${ }^{37}$ Because the AgNPs absorb at the laser wavelength (the laser emission is on the red side of the localized plasmon resonance as can be seen in Figure 3), the laser threshold is seen to increase upon target binding (Figure $6 a)$; meanwhile, the output intensity at a given pump level 
drops (Figure 6a). The presence of AgNPs also leads to a reduction of the slope of the laser transfer function. We surmise that the observed threshold increasing (and slope decreasing) effect of the AgNP on the DFB platform is due to the optical losses following a binding-dependent modal loss caused by immobilization of the target ODNs (see SI2, Nanoparticle Theory). In summary, the modal gain needed for laser oscillation must match the overall losses and therefore the pump intensity at threshold $I_{\mathrm{pth}}$ is proportional to these losses,

$$
I_{\mathrm{pth}}=\frac{h \nu_{\mathrm{p}}}{\alpha_{\mathrm{p}}} \frac{\alpha+\Gamma_{1} \alpha_{\mathrm{NP}}}{\Gamma_{\mathrm{a}} \sigma \tau_{32}}
$$

where $\alpha$ is the modal loss of the initial laser, $\alpha_{\mathrm{NP}}$ is the loss due to bound AgNPs, $\Gamma_{1}$ is a parameter representing the overlap of the laser mode intensity with the AgNPs, $\alpha_{\mathrm{p}}$ is the absorption at the pump wavelength, and $h \nu_{\mathrm{p}}$ is the energy of the pump photons. The ratio of the threshold pump energy before, $E_{b}$, and after, $E_{a}$, functionalization is then simply

$$
\frac{E_{\mathrm{a}}}{E_{\mathrm{b}}} \propto \frac{I_{\text {pth_a }}}{I_{\text {pth_b }}}=\Gamma_{1} \frac{\alpha_{\mathrm{NP}}}{\alpha}+1
$$

$I_{\text {pth_b }}$ and $I_{\text {pth_a }}$ are the pump intensities at threshold before and after functionalization, respectively. At low analyte concentration, $\alpha_{\mathrm{NP}}$ is expected to be linear with the concentration $x$. Under these conditions the laser threshold increases linearly with $x$ as given by (see SI2, Nanoparticle Theory)

$$
\frac{E_{\mathrm{a}}}{E_{\mathrm{b}}}=C x+1
$$

$C$ is a constant linked to the binding affinity and to $\alpha$.

The transfer functions for lasers were measured before and after incubation at different analyte concentrations (0, 11.5, 23, and $48.5 \mathrm{pM})$. Figure $6 \mathrm{a}$ shows the example of the laser transfer functions before and after incubation with $23 \mathrm{pM}$. The thresholds $E_{\mathrm{b}}$ and $E_{\mathrm{a}}$, identified by arrows, were calculated from energy readings taken at the same pump spot; the pump laser was blocked during incubation periods and between readings. While we focus here on laser intensity measurements and threshold, we note that no significant changes to the central emission wavelength (see SI3, NP Spectral Effects) of the laser upon target binding were detected (within a $\pm 0.13 \mathrm{~nm}$ resolution); minor changes in wavelength and line width were accounted for during threshold calculations fitting the DFB laser output with a Gaussian curve. ${ }^{54}$ The ratio $\frac{E_{\mathrm{a}}}{E_{\mathrm{b}}}$, which increases with the concentration, is plotted in Figure $6 \mathrm{~b}$ along with the linear fit using eq 3 with $C=0.039 \mathrm{pM}^{-1}$. The LOD by threshold monitoring is $11.5 \mathrm{pM}$ by observation; a lower limit may be obtained by increasing the resolution of AgNP concentrations that are tested. Altering the incubation time could be attempted to lower the LOD, as a longer incubation time might allow more hybridization to occur. Bringing the laser emission in alignment with the NP resonance would increase absorption and therefore should lower the LOD as well. At a concentration of $48.5 \mathrm{pM}$, the $E_{\mathrm{a}}$ value was unobtainable as the laser could not reach the threshold. The reason for this is that for a given DFB laser structure (i.e., a given $\operatorname{Tr}$ thickness), the modal gain has a maximum, called the saturated gain, which cannot be exceeded. Once the modal gain is saturated, increasing the pump energy does not increase the gain as the population of $\operatorname{Tr}$ molecules is fully inverted. If the added loss due to analyte hybridization makes the gain at a threshold higher than this saturated gain, then laser oscillation cannot be obtained. This effect limits the dynamic range of sensing by laser threshold monitoring. The dynamic range could be increased, however, by increasing the thickness of the $\operatorname{Tr}$ film, which would raise the saturated gain value.

Figure 6c shows the corresponding SERS map of the laser surface after incubation, clearly confirming the increased bound analytes for increasing concentration.

\section{CONCLUSION}

Our approach demonstrates the feasibility of DNA-based sensing with an organic semiconductor DFB laser. A successful, effective immobilization strategy for ODN probes on an OS surface has been identified. With silver NP-functionalized analytes, the laser threshold has been shown to respond to binding events for concentration at and above $11.5 \mathrm{pM}$; alterations to incubation time could lower this. With the use of OSs with different emission frequencies and NPs with different absorption spectra and by tuning the gain material thickness, it is expected that the sensitivity and dynamic range could be tailored for specific applications. Not only have we confirmed a polyelectrolyte-anchored, click-chemistry protocol as a viable method of DFB laser surface functionalization, but also we have demonstrated the capture of matching ODN sequences and the specificity of the protocol. With the current trends toward ODN Aptamer probes ${ }^{55-57}$ in biosensing and the reduced complexity in comparison to traditional antibodybased sensing protocols, the novel ODN approach outlined here demonstrated with OS DFB lasers is an important stepping stone to specific, low cost optical biosensing applications.

\section{ASSOCIATED CONTENT}

\section{S Supporting Information}

The Supporting Information is available free of charge on the ACS Publications website at DOI: 10.1021/acs.langmuir.8b01313.

SI1, SEM Imaging, SEM images of the surface of a DFB laser with and without probe functionalization after exposure to target bound AgNPs in solution; SI2, Nanoparticle Theory, nanoparticle effect on laser mode with equations/theory (PDF)

SI3, NP Spectral Effects: 0 pM DFB spectra and 22.9 pM DFB spectra (before/after) (PDF)

\section{AUTHOR INFORMATION}

\section{Corresponding Author}

*E-mail: nicolas.laurand@strath.ac.uk.

ORCID ${ }^{\circ}$

G. McConnell: 0000-0001-8764-6127

G. A. Burley: 0000-0002-4896-113X

\section{Present Addresses}

\#P. J. Skabara is now at the University of Glasgow School of Chemistry.

${ }^{\nabla}$ A. L. Kanibolotsky is at the University of Glasgow School of Chemistry, being on leave from The National Academy of Sciences of Ukraine.

\section{Notes}

The authors declare no competing financial interest. 
All data underpinning this publication are openly available from the University of Strathclyde KnowledgeBase at http:// dx.doi.org/10.15129/1316da75-360d-4cf7-b9e3$57 \mathrm{~d} 0 \mathrm{~b} 18 \mathrm{~d} 2190$.

\section{ACKNOWLEDGMENTS}

This work was supported and funded by the Medical Devices CDT of Strathclyde University EPSRC grant number EP/ F50036X/1. A.L.K. thanks the EPSRC for funding (EP/ N009908/1). P.J.S. thanks the Royal Society for a Wolfson Research Merit Award.

\section{REFERENCES}

(1) Yuan, L. Q.; de Jesus Perez, V.; Liao, X. B.; Krol, M.; Yeh, C. H. MicroRNA and Cardiovascular Disease 2016. BioMed Res. Int. 2017, 2017, 3780513.

(2) Naga Prasad, S. V.; Gupta, M. K.; Duan, Z. H.; Surampudi, V. S.; Liu, C. G.; Kotwal, A.; Moravec, C. S.; Starling, R. C.; Perez, D. M.; Sen, S.; Wu, Q.; Plow, E. F.; Karnik, S. A unique microRNA profile in end-stage heart failure indicates alterations in specific cardiovascular signaling networks. PLoS One 2017, 12 (3), e0170456.

(3) Cordes, K. R.; Srivastava, D. MicroRNA regulation of cardiovascular development. Circ. Res. 2009, 104 (6), 724-732.

(4) Zhang, X. B.; Chen, B. S. Perspective of microRNA in cardiovascular-associated diseases. Zhonghua Xin Xue Guan Bing Za Zhi 2008, 36 (7), 661-663.

(5) Justino, A.; Dias, P.; Pina, M. J.; Sousa, S.; Cirnes, L.; Sousa, A. B.; Machado, J. C.; Costa, J. L. Comprehensive massive parallel DNA sequencing strategy for the genetic diagnosis of the neuro-cardiofacio-cutaneous syndromes. Eur. J. Hum. Genet. 2015, 23 (3), 347353.

(6) Song, H.; Nan, Y.; Cheng, X. W. Circulating cf-DNA: a promising, noninvasive tool for assessment of early cardio-metabolic risk. Atherosclerosis 2014, 233 (1), 307-309.

(7) Elliott, H. R.; Tillin, T.; Chaturvedi, N.; Hughes, A. D.; McArdle, W.; Smith, G. D.; Frayling, T. M.; Ebrahim, S.; Relton, C. L. DNA methylation, cardio metabolic risk and type 2 diabetes in south Asians and Europeans. Clin. Epigenet. 2013, 6, 4.

(8) Hu, R.; Li, G.; Kamijo, Y.; Aoyama, T.; Nakajima, T.; Inoue, T.; Node, K.; Kannagi, R.; Kyogashima, M.; Hara, A. Serum sulfatides as a novel biomarker for cardiovascular disease in patients with end-stage renal failure. Glycoconjugate J. 2007, 24 (9), 565-571.

(9) Lindahl, B. Diagnosis and management of patients with suspected acute myocardial infarction. Scand. J. Clin. Lab. Invest. 2005, 65, 93-98.

(10) Willcox, B. J.; Abbott, R. D.; Yano, K.; Rodriguez, B. L.; Willcox, D. C.; Curb, J. D. C-reactive protein, cardiovascular disease and stroke: new roles for an old biomarker. Expert Rev. Neurother. 2004, 4 (3), 507-518.

(11) Hunter, C.; Becker, G.; Breite, A.; Anderson, L. Developing peptide MRM-based assays for cardiovascular biomarker proteins in plasma using a hybrid triple quadrupole linear ion trap mass spectrometer. Mol. Cell. Proteomics 2005, 4 (8), S217-S217.

(12) Hulka, B.; Wilcosky, T. Biological markers in epidemiologic research. Arch. Environ. Health 1988, 43 (2), 83.

(13) Bruins Slot, M. H.; van der Heijden, G. J.; Stelpstra, S. D.; Hoes, A. W.; Rutten, F. H. Point-of-care tests in suspected acute myocardial infarction: a systematic review. Int. J. Cardiol. 2013, 168 (6), 5355-5362.

(14) Reichlin, T.; Hochholzer, W.; Bassetti, S.; Steuer, S.; Stelzig, C.; Hartwiger, S.; Biedert, S.; Schaub, N.; Buerge, C.; Potocki, M.; Noveanu, M.; Breidthardt, T.; Twerenbold, R.; Winkler, K.; Bingisser, R.; Mueller, C. Early Diagnosis of Myocardial Infarction with Sensitive Cardiac Troponin Assays. N. Engl. J. Med. 2009, 361 (9), 858-867.

(15) Balboni, I.; Chan, S. M.; Kattah, M.; Tenenbaum, J. D.; Butte, A. J.; Utz, P. J. MULTIPLEXED PROTEIN ARRAY PLATFORMS
FOR ANALYSIS OF AUTOIMMUNE DISEASES. Annu. Rev. Immunol. 2006, 24 (1), 391-418.

(16) Kost, G. J.; Tran, N. K.; Tuntideelert, M.; Kulrattanamaneeporn, S.; Peungposop, N. Katrina, the Tsunami, and Point-of-Care TestingOptimizing Rapid Response Diagnosis in Disasters. Am. J. Clin. Pathol. 2006, 126 (4), 513-520.

(17) Spindel, S.; Sapsford, E. K. Evaluation of Optical Detection Platforms for Multiplexed Detection of Proteins and the Need for Point-of-Care Biosensors for Clinical Use. Sensors 2014, 14 (12), 22313.

(18) Martinez-Perdiguero, J.; Retolaza, A.; Bujanda, L.; Merino, S. Surface plasmon resonance immunoassay for the detection of the TNFalpha biomarker in human serum. Talanta 2014, 119, 492-497.

(19) Morales-Vidal, M.; Boj, P. G.; Quintana, J. A.; Villalvilla, J. M.; Retolaza, A.; Merino, S.; Díaz-García, M. A. Distributed feedback lasers based on perylenediimide dyes for label-free refractive index sensing. Sens. Actuators, B 2015, 220, 1368-1375.

(20) Jackowski, G. Method and device for diagnosing and distinguishing chest pain in early onset thereof. US5604105B1, 1996/09/05/Application date, 1996.

(21) Washburn, A. L.; Gunn, L. C.; Bailey, R. C. Label-Free Quantitation of a Cancer Biomarker in Complex Media Using Silicon Photonic Microring Resonators. Anal. Chem. 2009, 81 (22), 94999506.

(22) Baaske, M.; Vollmer, F. Optical Resonator Biosensors: Molecular Diagnostic and Nanoparticle Detection on an Integrated Platform. ChemPhysChem 2012, 13 (2), 427-436.

(23) Armani, A. M.; Kulkarni, R. P.; Fraser, S. E.; Flagan, R. C.; Vahala, K. J. Label-free, single-molecule detection with optical microcavities. Science 2007, 317 (5839), 783-787.

(24) Shamah, S. M.; Cunningham, B. T. Label-free cell-based assays using photonic crystal optical biosensors. Analyst 2011, 136 (6), $1090-1102$

(25) Cunningham, B. T.; Li, P.; Schulz, S.; Lin, B.; Baird, C.; Gerstenmaier, J.; Genick, C.; Wang, F.; Fine, E.; Laing, L. Label-free assays on the BIND system. J. Biomol. Screening 2004, 9 (6), 481490.

(26) Chou, T. C.; Doong, R. A. ANYL 222-Gold nanoparticle-based photonic crystal biosensor for tumor markers' detection. Abstracts of Papers of the American Chemical Society 2009, 238.

(27) Homola, J.; Yee, S. S.; Gauglitz, G. Surface plasmon resonance sensors: review. Sens. Actuators, B 1999, 54 (1-2), 3-15.

(28) Koubova, V.; Brynda, E.; Karasova, L.; Skvor, J.; Homola, J.; Dostalek, J.; Tobiska, P.; Rosicky, J. Detection of foodborne pathogens using surface plasmon resonance biosensors. Sens. Actuators, B 2001, 74 (1-3), 100-105.

(29) Haughey, A. M.; McConnell, G.; Guilhabert, B.; Burley, G. A.; Dawson, M. D.; Laurand, N. Organic Semiconductor Laser Biosensor: Design and Performance Discussion. IEEE J. Sel. Top. Quantum Electron. 2016, 22 (1), 6.

(30) Heydari, E.; Buller, J.; Wischerhoff, E.; Laschewsky, A.; Döring, S.; Stumpe, J. Label-Free Biosensor Based on an All-Polymer DFB Laser. Adv. Opt. Mater. 2014, 2 (2), 137-141.

(31) Shopova, S. I.; Rajmangal, R.; Nishida, Y.; Arnold, S. Ultrasensitive nanoparticle detection using a portable whispering gallery mode biosensor driven by a periodically poled lithium-niobate frequency doubled distributed feedback laser. Rev. Sci. Instrum. 2010, 81 (10), 103110.

(32) Retolaza, A.; Martinez-Perdiguero, J.; Merino, S.; MoralesVidal, M.; Boj, P. G.; Quintana, J. A.; Villalvilla, J. M.; Díaz-García, M. A. Organic distributed feedback laser for label-free biosensing of ErbB2 protein biomarker. Sens. Actuators, B 2016, 223, 261-265.

(33) Li, Z.; Zhang, Z.; Emery, T.; Scherer, A.; Psaltis, D. Single mode optofluidic distributed feedback dye laser. Opt. Express 2006, 14 (2), 696-701.

(34) Tsutsumi, N.; Ishibashi, T. Organic dye lasers with distributed Bragg reflector grating and distributed feedback resonator. Opt. Express 2009, 17 (24), 21698-703. 
(35) Han, S. G.; Lim, J.; Shin, J.; Lee, S. M.; Park, T.; Yoon, J.; Woo, K.; Lee, H.; Lee, W. Optically pumped distributed feedback dye lasing with slide-coated $\mathrm{TiO}(2)$ inverse-opal slab as Bragg reflector. Opt. Lett. 2014, 39 (16), 4743-4746.

(36) Katarkevich, V. M.; Rubinov, A. N.; Efendiev, T.; Anufrik, S. S.; Koldunov, M. F. Highly efficient solid-state distributed feedback dye laser based on polymer-filled nanoporous glass composite excited by a diode-pumped solid-state Nd:LSB microlaser. Appl. Opt. 2015, 54 (26), 7962-7972.

(37) Haughey, A. M.; Guilhabert, B.; Kanibolotsky, A. L.; Skabara, P. J.; Burley, G. A.; Dawson, M. D.; Laurand, N. An organic semiconductor laser based on star-shaped truxene-core oligomers for refractive index sensing. Sens. Actuators, B 2013, 185, 132-139.

(38) Herrnsdorf, J.; Guilhabert, B.; Chen, Y.; Kanibolotsky, A.; Mackintosh, A.; Pethrick, R.; Skabara, P.; Gu, E.; Laurand, N.; Dawson, M. Flexible blue-emitting encapsulated organic semiconductor DFB laser. Opt. Express 2010, 18 (25), 25535-25545.

(39) Liu, X.; Prinz, S.; Besser, H.; Pfleging, W.; Wissmann, M.; Vannahme, C.; Guttmann, M.; Mappes, T.; Koeber, S.; Koos, C.; Lemmer, U. Organic semiconductor distributed feedback laser pixels for lab-on-a-chip applications fabricated by laser-assisted replication. Faraday Discuss. 2014, 174, 153-164.

(40) Keefe, A. D.; Pai, S.; Ellington, A. Aptamers as therapeutics. Nat. Rev. Drug Discovery 2010, 9 (7), 537-550.

(41) Song, K.-M.; Lee, S.; Ban, C. Aptamers and Their Biological Applications. Sensors 2012, 12 (1), 612.

(42) Lu, M.; Choi, S. S.; Irfan, U.; Cunningham, B. T. Plastic distributed feedback laser biosensor. Appl. Phys. Lett. 2008, 93 (11), 111113.

(43) Tan, Y.; Ge, C.; Chu, A.; Lu, M.; Goldshlag, W.; Huang, J.; Pokriyal, A.; George, S.; Cunningham, B. T. Plastic-based distributed feedback laser biosensors in microplate format. IEEE Sens. J. 2012, 12 (5), 1174-1180.

(44) Swierczewska, M.; Liu, G.; Lee, S.; Chen, X. High-sensitivity nanosensors for biomarker detection. Chem. Soc. Rev. 2012, 41 (7), 2641-2655.

(45) Rozkiewicz, D. I.; Gierlich, J.; Burley, G. A.; Gutsmiedl, K.; Carell, T.; Ravoo, B. J.; Reinhoudt, D. N. Transfer printing of DNA by "click" chemistry. ChemBioChem 2007, 8 (16), 1997-2002.

(46) El-Sagheer, A. H.; Brown, T. Click chemistry with DNA. Chem. Soc. Rev. 2010, 39 (4), 1388-13405.

(47) Obeid, S.; Busskamp, H.; Welte, W.; Diederichs, K.; Marx, A. Interactions of non-polar and "Click-able" nucleotides in the confines of a DNA polymerase active site. Chem. Commun. (Cambridge, U. K.) 2012, 48 (67), 8320-8322.

(48) Timper, J.; Gutsmiedl, K.; Wirges, C.; Broda, J.; Noyong, M.; Mayer, J.; Carell, T.; Simon, U. Surface "click" reaction of DNA followed by directed metalization for the construction of contactable conducting nanostructures. Angew. Chem., Int. Ed. 2012, 51 (30), $7586-7588$.

(49) Kashmery, H. A.; Thompson, D. G.; Dondi, R.; Mabbott, S.; Graham, D.; Clark, A. W.; Burley, G. A. SERS enhancement of silver nanoparticles prepared by a template-directed triazole ligand strategy. Chem. Commun. 2015, 51 (65), 13028-13031.

(50) Belton, C., R.; Kanibolotsky Alexander, L.; Kirkpatrick, J.; Orofino, C.; Elmasly Saadeldin, E. T.; Stavrinou Paul, N.; Skabara Peter, J.; Bradley Donal, D. C. Location, Location, Location Strategic Positioning of 2,1,3-Benzothiadiazole Units within Trigonal Quaterfluorene-Truxene Star-Shaped Structures. Adv. Funct. Mater. 2013, 23 (22), 2792-2804.

(51) Wang, Y.; Tsiminis, G.; Yang, Y.; Ruseckas, A.; Kanibolotsky, A. L.; Perepichka, I. F.; Skabara, P. J.; Turnbull, G. A.; Samuel, I. D. W. Broadly tunable deep blue laser based on a star-shaped oligofluorene truxene. Synth. Met. 2010, 160 (13), 1397-1400.

(52) Kanibolotsky, A. L.; Berridge, R.; Skabara, P. J.; Perepichka, I. F.; Bradley, D. D. C.; Koeberg, M. Synthesis and Properties of Monodisperse Oligofluorene-Functionalized Truxenes: Highly Fluorescent Star-Shaped Architectures. J. Am. Chem. Soc. 2004, 126 (42), 13695-13702.
(53) Mabbott, S.; Thompson, D.; Sirimuthu, N.; McNay, G.; Faulds, K.; Graham, D. From synthetic DNA to PCR product: detection of fungal infections using SERS. Faraday Discuss. 2016, 187 (0), 461472 .

(54) Herrnsdorf, J. Organic lasers and nanostructred organic films for hybrid integration; University of Strathclyde: Glasgow, 2012.

(55) Ostatna, V.; Vaisocherova, H.; Homola, J.; Hianik, T. Effect of the immobilisation of DNA aptamers on the detection of thrombin by means of surface plasmon resonance. Anal. Bioanal. Chem. 2008, 391 (5), 1861-1869.

(56) Li, X.; Li, W.; Zhang, S. Chemiluminescence DNA biosensor based on dual-amplification of thrombin and thiocyanuric acid-gold nanoparticle network. Analyst 2010, 135 (2), 332-336.

(57) Li, X.; Xia, J.; Li, W.; Zhang, S. Multianalyte electrochemical biosensor based on aptamer- and nanoparticle-integrated bio-barcode amplification. Chem. - Asian J. 2010, 5 (2), 294-300. 